\title{
Poliquistosis renal
}

\author{
J. García Rodríguez, A. Jalón Monzón, A. Sánchez Trilla, J. Regadera Sejas, \\ J.J. Rodríguez Martínez, O. Rodríguez Faba, R.C. González Álvarez
}

Servicio de Urología I. Hospital Central de Asturia. Oviedo.

Actas Urol Esp 2005; 29 (5): 532

$\mathrm{P}$ resentamos el caso de una paciente trasplantada renal por enfermedad poliquística, como se objetiva en la imagen de la Tac (Fig. 1), que precisó nefrectomía renal derecha (Fig. 2) por absceso quístico.

Se trata de una enfermedad de transmisión autosómica dominante, causada por mutación del gen PKD1 localizado en el brazo corto del cromosoma 16 en aproximadamente el 85\% de los casos.

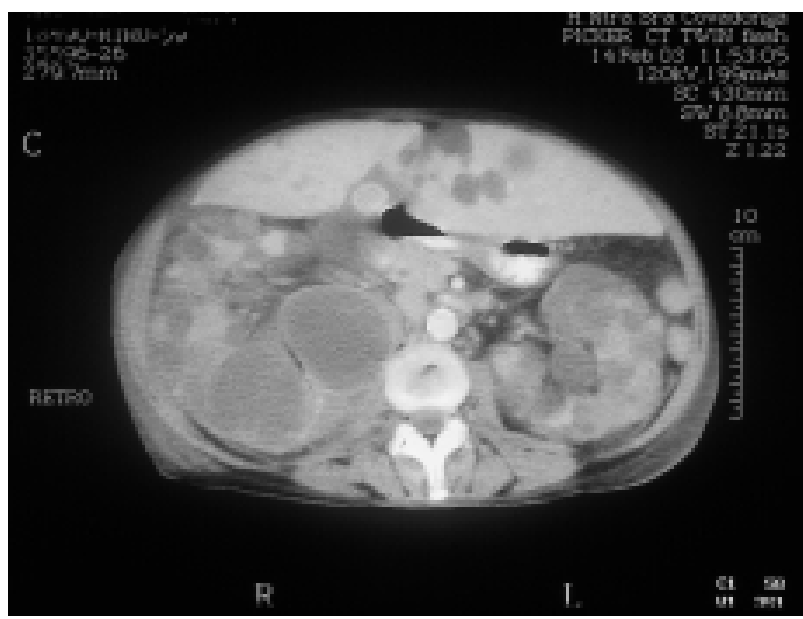

FIGURA 1
La presentación clínica suele producirse en la cuarta década de la vida, generalmente como hipertensión arterial, causada por hipersecreción de renina, aunque sus manifestaciones cardinales son los quistes renales y la insuficiencia renal. Puede asociar alteraciones extrarrenales siendo la más común la hepatopatía quística (10-75\%).

El objetivo del tratamiento es preservar la función renal, controlando la hipertensión, aunque muchos pacientes terminan por precisar diálisis o trasplante, como en nuestro caso.

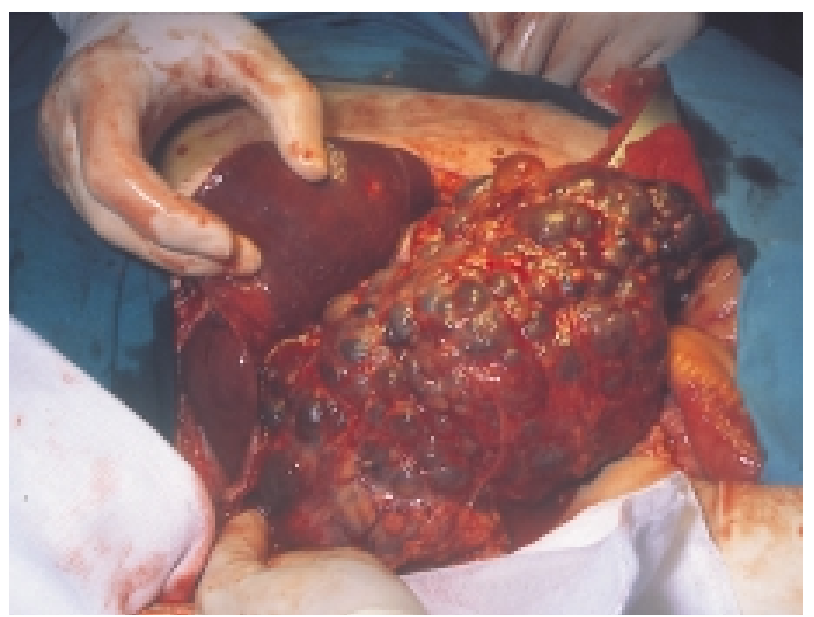

FIGURA 2 